\title{
UN LEMA A REVISAR EN PLINIO, NH XXXII 149
}

At Plinius, NH XXXII 149, the author conjectures ...lepus... lupus... for ...elepris... lepus...

$\mathrm{La}$ indefinición del entorno y la desconfianza en la meticulosidad de Plinio el Viejo conspiran para encubrir lo simbolizado por el desaliño más indefenso de cualquier texto manuscrito ': ... lucerna, telepris (RdT elaepris $V$ elepas $B$ ), lamirus, lepus... (NH XXXII 149). La inercia de editores y lexicógrafos posteriores a Jan favoreció el enquistamiento de $<l>$ elepris (gr. $\lambda \varepsilon \lambda \varepsilon \pi \rho i$, hápax de Hesiquio), hasta que un cultivador señero del tema de la fauna marina supo reconocer parejos méritos en [e]lepas (gr. $\lambda \varepsilon \pi \dot{\alpha} \varsigma$ ) de Sillig ${ }^{2}$. Estimo que cabe abordar el pasaje en litigio desde una perspectiva más amplia, esto es, pliniana; y como justo en la decisión editorial descansa una entrada de los diccionarios latinos cuando menos incierta ${ }^{3}$, el menoscabo de aquélla promueve el desahucio de ésta. Ganancia mínima, de cierto, pero con repercusión en una tarea de interés y dificultad máximos, cual es la fijación puntual del inventario de palabras efectivamente documentables en latín.

A lo que sospecho, tal vez tenga algo que ver con la gestación de la mácula una de las paradojas para mí más desconcertantes del catálogo recapitulativo de animales acuáticos (XXXII 144-154). Me refiero a la circunstancia de que una especie tan estimada de los romanos y repetidamente mentada por Plinio como lupus ${ }^{4}$, no aparece en la letra perti-

\footnotetext{
'Salta a la vista que una enumeración alfabética de voces con lateral inicial repele. todo cuanto empiece de otra manera.

${ }^{2}$ E. de Saint-Denis, «Additions et rectifications au vocabulaire des bêtes aquatiques en latin", $R P h$ 40, 1966, pp. 241-242. Por un azar gracioso esta rancia conjetura aparece relegada al Index en su edición (Pline l'Ancien, Histoire Naturelle, Livre XXXII, París, Les Belles Lettres, 1966).

'Otra parecer ser la opinión de los redactores del OLD (Oxford Latin Dictionary): *lelepris... An unidentified fish" (Fasc. IV, 1973, s.u.).

4 Cf. De Saint-Denis, Le vocabulaire des animaux marins en latin classique, París, Klincksieck, 1947, Pp. 59-61; D. A. W. Thompson, A Glossary of Greek Fishes, London, Oxford University Press, 1947, pp. 141-142. Ya que sale el nombre de la lubina, no es la presente
} 
nente de la sección consagrada a peculiares maris '. En procura de una explicación que no sea la socorrida de apelar a inconsistencia, por el concepto de desbarajuste en el fichero del autor, se me puso en el magin la que ahora presento: si reconstruimos una secuencia primigenia ...lucerna, lepus, lamirus, lupus..., de inmediato se descubre que el último miembro ocuparía una posición harto propicia para sufrir en cualquier momento los efectos usurpatorios de una Perseverationsfehler (desencadenada por el cercano y casi homófono lepus, presumiblemente antes de su propia desfiguración). Tanto la bilocación que esto implica (es decir: ...lepus... lepus...) como la producción de fantasmas (tal etiqueta merecen las variantes el(a)epris/elepas, que acaso remonten a un elepus del arquetipo) figuran en el repertorio de percances inherentes al desempeño del oficio de copia $^{2}$, y no se ha de sonrojar quien los esgrima con fundamento.

Se argüirá que Jan y Sillig ofrecen el atractivo de la sencillez suprema, y que el segundo cuenta a su favor con la indiscutida autoridad del vetusto códice $B$ (ambergensis). Pero en puntos de economía paleográfica cumple evitar simplificaciones, que, si bien se mira, añadir o cancelar una letra no son intervenciones de naturaleza diferente a las de suplir, remover o desplazar una palabra, y hasta una línea entera si se tercia; y en lo que atañe a la deposición confusa de un testigo de la tradición en general fiable, la cautela más bien reclama renovar los interrogatorios por ver de sonsacarlo: la bondad de un testimonio depende, a las veces, de la presión inquisidora que sobre aquél se ejerza.

mala ocasión para avisar a los diccionaristas de la oportunidad de asumir (lo que no ha hecho $O L D$, Fasc. V, 1976) la brillante observación de Thompson (Glossary, p. 58), según el cual Plin. NH XXXI 95 Vitium huius est aliex... Foroiulienses piscem ex quo faciunt lupum appellant alude a la anchoa. (No convence la reserva de H. Leitner, Zoologische Terminologie beim Älteren Plinius, Hildesheim, Verlag Dr. H. A. Gerstenberg, 1972, p. 158, s.u. lupus 2: *... es ist aber durchaus möglich, dass hie: ebenfalls eine Art der Meeresbarsche [Serranidae] in Frage kommt*).

' Aunque con mayor rigor científico se esperaría en XXXII 145 (entre communes amni tantum ac mari: la lubina es un anádromo que desde el mar remonta los ríos para desovar), tenemos los ejemplos de acipenser y anguilla alistados como si fueran de mar sólo. En todo cas(), discrepo) de J. A. Richmond (-Pliny's Catalogue of Fishes*, Hermes 99, 1971, pp. 138-140) en cuanto a la conveniencia de intercalar lupus en XXXII 152 (con los ab Ouidio posita nomina, quae apud neminem alium reperiuntur), porque encuentro indicios suficientes como para no hacer incurrir a Plinio en la contradicción de afirmar que lo había leído exclusivamente en Halieutica: NH IX 61 Postea praecipuam auctoritatem fuisse lupo et asellis Nepos Cornelius et Laberius poeta mimorum tradidere; IX 185 Nigidius auctor est praerodere caudam mugili lupum.

${ }^{2}$ De ditografia hay poco antes (XXXII 147) un ejemplo similar: acancrorum genera $\left(B^{\prime}\right)$ en lugar de cancrorum (VR). 
Significa ello que ninguna emendación se legitima sólo por la menor cuantía del desembolso ', sino por su necesidad y verosimilitud. A uno y otro requerimiento pretende dar satisfacción la sugerencia precedente, pues (a) con base en el principio rotundamente sano de que Plinio no podría asentir a todas y cada una de las lecciones actuales del texto heredado, muestra una incongruencia que en el orden normal de las cosas no debería ser de origen; y (b) sin aparatosidades, por simple reducción a su primitiva plaza de lepus (también familiar al autor ${ }^{2}$, por tanto intachable en la lista antes o después), habilita el espacio preciso para la reposición del deseado lupus, faena que redunda en el desalojo de una innovación moderna carente de evidencia interna compulsiva (no es garante satisfactorio la mera semejanza entre la lectura de un grupo de mss. de menor crédito y un vocablo griego singular y opaco ${ }^{3}$ ).

Ahora bien: por mor de la verdad viene obligado el estudioso a refrenar la nativa proclividad a poner los hallazgos ajenos siquiera un escaño por debajo de los propios. En su consecuencia, sin ambages alabo la hechura artesanal de la corrección lepas, en apariencia peor justificadora de las variantes y sin respaldo definitivo en Plinio, y aun creo poder mejorar un tanto los argumentos apuntados por De Saint-Denis. Porque, desechado por improbable que el engendro elepas oculte un préstamo oral ${ }^{4}$, lo cierto es que la presencia en el mismo apartado de términos tomados del griego sin acomodación lingüística y ausentes del resto de la obra, depura de buena dosis de arbitrariedad la hipótesis de un ingreso por vía culta e invita a confirmarla de una vez por todas. En previsión de que esto ocurra, no advierto indiscreción en anticipar que el acierto de la propuesta de Sillig no invalida por sí mismo los cargos que provocaron la mía, ni tampoco en dejar caer una eventual alternativa conciliadora de ambas, a saber: ...lucerna, [e]lepas, <lepus>, lamirus, lupus... (Su complejidad no es realmente tal, porque (1) a la vera de lepas, la desaparición haplográfica de lepus resulta accidente tan irrelevante que no restaría un adarme de viabilidad transcripcional al todo; (2) no hay riesgo en asegurar que, de haber suministrado eso la tradición, írrito empeño sería el de buscarle tachas por razones de contenido;

\footnotetext{
'Si el criterio de economía externa $\rightarrow$ más crudamente, de halago sensorial - fuera la única pauta a seguir, la cuestión se zanjaría fácilmente postulando un falso corte de palabras desde lucernae, lepas.

${ }^{2}$ El lugar, estudiado aparte, se atestigua una decena de veces en el libro XXXII (según Index ed. De Saint-Denis).

${ }^{3}$ Cf. Thompson, Glossary, p. 147.

- En ese caso tendríamos para el nom. singular una latinización le-/lopada deducible de las formas plurales de Plauto: Cas. 493 lepadas; Rud. 297 y frg. inc. 102 lopadas.
} 
y (3) el suplemento no cuestiona por fuerza la capacidad de Plinio para la más elemental de las operaciones aritméticas ').

Es saber común que el negocio de la crítica textual estriba, al cabo, en aquilatar las probabilidades de los testimonios, pero no tanto que la piedra de toque para este menester no puede ser otra que la referencia al conjunto en que se integran; el procedimiento contrario recuerda al dicho inglés que previene de la inutilidad de tentar a confeccionar monederos de seda con oreja de cerda. Pues bien, antes de concluir.y para mejor cimentación de lo esbozado arriba en (a), quisiera señalar que precisamente la pretensión de exhaustividad para el catálogo ${ }^{2}$ hace menos probable la omisión en él de un ictiónimo típicamente latino y con sobrada probanza en Plinio (lupus), que el registro en transliteración (lelepris) de otro griego del que no es posible, por hoy, discernir si llegó a su noticia.

RAMÓN BALTAR Veloso

\footnotetext{
' En efecto, a pesar del notable avance que supone el articulo citado en p. 124, n. 1, todavía queda oscuro el detalle de cómo operó Plinio para obtener las cifras, en principio reconciliables, de 144 genera y 176 nomina, declarados respectivamente en el prefacio al catálogo (XXXII 142) y en el índice general (I 32, 53); por lo que, incluso si atinó Richmond en las sumas parciales de las varias listas en que la recapitulación se desglosa, se intuye margen teórico para barajar otras posibilidades y combinaciones, como la inserción y/o supresión de términos. Me anima a rebuscar en esta línea la triple creencia de que: (1) la fiel reproducción de tamaña retahlla de tecnicismos, en general rarezas para el no versado, pide punto menos que inspiración divina en el amanuense; (2) marra el británico en el recurso a expedientes violentos con achaque de solventar algún que otro extremo perturbador para su recuento; y (3) una lectura aberrante del Bambergensis, cymosdenti (XXXII 148), insinúa amalgama de cy<pri>nos, denti<x> (cf. Glotta 55, 1977, pp. 91-93), por tanto ampliación de los elementos a tomar en cuenta.

${ }^{2}$ Cf. XXXII 142 ...non alienuem uidetur indicare per tot maria... animalia centum quadraginta quattuor omnino generum esse...
} 